\title{
Prevalence and Morphologic Features of Ponticulus Posticus in Koreans: Analysis of 312 Radiographs and 225 Three-dimensional CT Scans
}

\author{
Kyeong Hwan Kim, Kun Woo Park, Tran Hoang Manh, \\ Jin Sup Yeom, Bong-Soon Chang, Choon-Ki Lee \\ Department of Orthopedic Surgery, Seoul National University School of Medicine, Seoul, Korea
}

\begin{abstract}
Study Design: A retrospective review of three-dimensional CT scan images and radiographs.
Purpose: To investigate the prevalence and morphologic features of ponticulus posticus in Koreans.

Overview of Literature: There has been little reported on the prevalence or morphologic characteristics of ponticulus posticus in Asians, predisposing them to vertebral artery injury during screw placement in the lateral mass of the atlas.

Methods: The presence and types of ponticulus posticus were investigated on 225 consecutive cervical three-dimensional CT scans and 312 consecutive digital lateral cephalometric head radiographs.

Results: Various spectra of ponticulus posticus were found in $26 \%$ of the CT scans and $14 \%$ of the radiographs.

Conclusions: Ponticulus posticus is a relatively common anomaly in Koreans. Therefore, the presence of this anomaly should be carefully examined for on radiographs before lateral mass screw placement. If ponticulus posticus is suspected or confirmed on radiographs, three-dimensional CT scanning should be considered before placement of lateral mass screws into the posterior arch, especially given its wide variation of size and shape.
\end{abstract}

Key Words: Ponticulus posticus, Atlas, Lateral mass screw

\section{Introduction}

Ponticulus posticus has recently been reported to predispose a catastrophic complication such as a vertebral artery injury, during the placement of lateral mass screws into the atlas. The Latin meaning of ponticulus posticus is "little posterior bridge" ", which describes a malformed bony bridge between the posterior portion of the superior articular process and the posterolateral portion of the superior margin of the posterior arch of the atlas. Ponticulus posticus forms the arcuate foramen that contains the vertebral artery and the suboccipital nerve and has been known to be a possible cause of posterior circulation strokes ${ }^{2}$ and migraines ${ }^{3}$. This condition had not been a matter of concern for spine surgeons until its surgical significance in the placement of screws into the lateral mass of the Atlas was recently report$\mathrm{ed}^{1}$. Young et al. ${ }^{4}$ reported that mistaking the ponticulus posticus for just a broad posterior arch of the atlas during C1 lateral mass screw placement could cause injury to the vertebral artery. Considering the catastrophic complication this could possibly cause, we need to understand the threedimensional morphologic features and the prevalence of this anomaly.

Prevalence of Ponticulus Posticus has been reported to be between $5.1 \%$ and $37.8 \%$ in the Western population ${ }^{3.5}$. We, however, could find only one report ${ }^{1}$ on its prevalence or morphologic characteristics in an Asian population. Therefore, we investigated the prevalence and morphologic features of ponticulus posticus in Koreans.

Corresponding author: Jin Sup Yeom, MD

Department of Orthopedic Surgery, Seoul National University Bundang Hospital

300 Goomi-dong, Bundang-gu, Sungnam, 463-707, Korea

Tel: +82-31-787-7195, Fax: +82-31-787-4056, E-mail: ortho@ hananet.net 


\section{Materials and Methods}

This study was approved by the institutional review board of our institution. First, we retrieved 1-mm interval cervical CT scan images of 225 consecutive patients over the age of eighteen taken in a large metropolitan teaching hospital. In most of those patients, CT scanning was ordered by orthopaedic surgeons or neurosurgeons for evaluation of cervical spine problems. There were 146 men and 79 women, and the average age was 45 (range, 18 to 87). All the images were retrieved in digital format from a picture archiving and communication system (PACS) server. Using personal computer-based software (V-works; Cybermed, Korea), these images were reconstructed into three-dimensional images, and carefully inspected for the presence and types of ponticuli.

Because the 225 patients examined above had cervical spine problems, we could not be sure whether the prevalence of ponticuli in these patients was an accurate representation of this condition in the normal Korean population. We therefore examined digital lateral cephalometric head radiographs of 315 consecutive patients over the age of eighteen, which were taken in the department of dentistry of the same hospital for evaluation of dental conditions, facial patterns, and jaw relationships, regardless of presence or absence of any cervical symptoms or headaches. Three patients with poor visualization of the posterior arch of the atlas due to overlapping of the mastoid process or the occiput were excluded. Of the 312 patients examined, 117 were men and 195 were women. The average age was 28 (range, 18 to 69). In each radiograph the presence of a ponticulus posticus and whether it was complete or partial were carefully inspected.

Statistical analysis was conducted with the chi-square test, using SPSS statistical package (version 12.0; SPSS Inc., Chicago, IL, USA). The level of significance was set at $\mathrm{p}<0.05$.

\section{Results}

Analysis of the 225 three-dimensional CT scans revealed ponticulus posticus in 58 patients, comprising 26\% (Table 1). The ponticulus was bilateral in 18 patients $(8 \%)$; on the right side alone in 17 patients (8\%); and on the left side

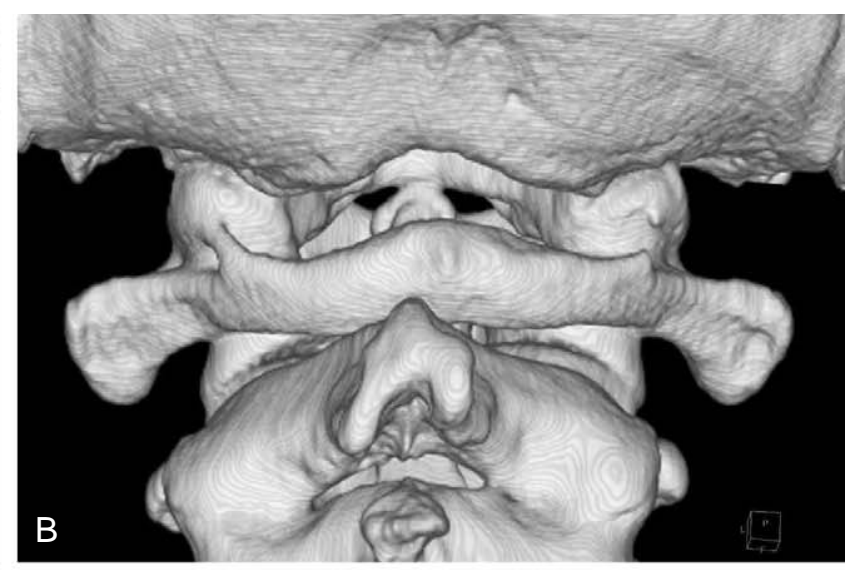

Fig. 1. Various types of ponticuli posticus seen on three-dimensional CT images. (A) Bilateral complete. (B) Complete on the left side and partial on the right side. (C) Unilateral complete on the right side. 
alone in 23 patients (10\%). The difference in frequency between the right and left sides was not statistically significant $(\mathrm{p}=0.45)$. Among the 76 ponticuli posticus observed on one or both sides in 58 patients, nine were complete and

Table 1. Prevalence of the ponticulus posticus in three-dimensional CT images of 225 patients

\begin{tabular}{lrrc}
\hline & \multirow{2}{*}{ Bilateral } & \multicolumn{2}{c}{ Unilateral } \\
\cline { 3 - 4 } & & \multicolumn{1}{c}{ Right } & \multicolumn{1}{c}{ Left } \\
\hline Complete & $1(0.4 \%)$ & $1(0.4 \%)$ & $2(0.9 \%)$ \\
Partial & $12(5.3 \%)$ & $16(7.1 \%)$ & $21(9.3 \%)$ \\
Complete+Partial* & $5(2.2 \%)$ & - & - \\
\hline Total & $18(8.0 \%)$ & $17(7.6 \%)$ & $23(10.2 \%)$ \\
\hline
\end{tabular}

*Complete ponticulus posticus on one side and partial ponticulus posticus on the other side.

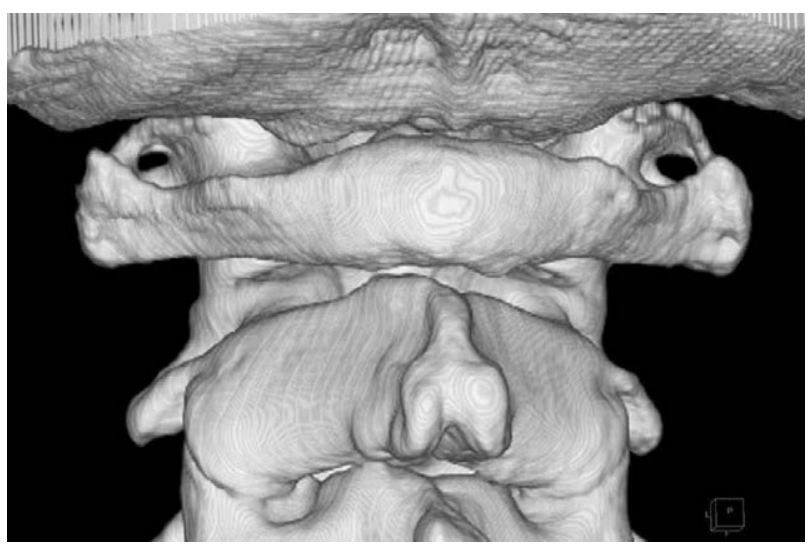

Fig. 2. Bilateral ponticuli lateralis seen on the three-dimensional CT scan. sixty-seven were incomplete (Fig. 1). There was no significant difference in the prevalence between men (37 out of $146,25 \%$ ) and women ( 21 out of $79,27 \%$; $=0.84$ ). We also observed ponticulus lateralis (Fig. 2), which is a bony bridge between the lateral aspect of the superior articular process and the transverse process, in 14 patients (6\%). All of them except one were unilateral, on the right side alone in 4 patients (2\%) and on the left side alone in 9 patients (4\%).

Analysis of the digital lateral cephalometric head radiographs of 312 patients revealed 14 complete and 30 incomplete ponticuli posticus (Fig. 3). Thus, the overall prevalence of ponticulus posticus in this patient population was $14 \%$, comprising $4 \%$ complete and $10 \%$ incomplete. This was significantly smaller than the prevalence in the cervical spine patients in whom CT scans were analyzed $(\mathrm{p}=0.0007)$. There was no significant difference in the prevalence between men (19 out of 117, 16\%) and women ( 25 out of $195,13 \%$; $\mathrm{p}=0.40$ ). In another 20 patients $(6 \%)$, spicules resembling partial ponticulus were found. Their sizes were not so large that we could not classify them as ponticuli posticus (Fig. 4). However, they might be a mild form of partial ponticulus posticus.

\section{Discussion}

Ponticulus posticus has become an important anomaly of the atlas, as the use of lateral mass screws for the fixation of the atlas has become common. Because putting this screw
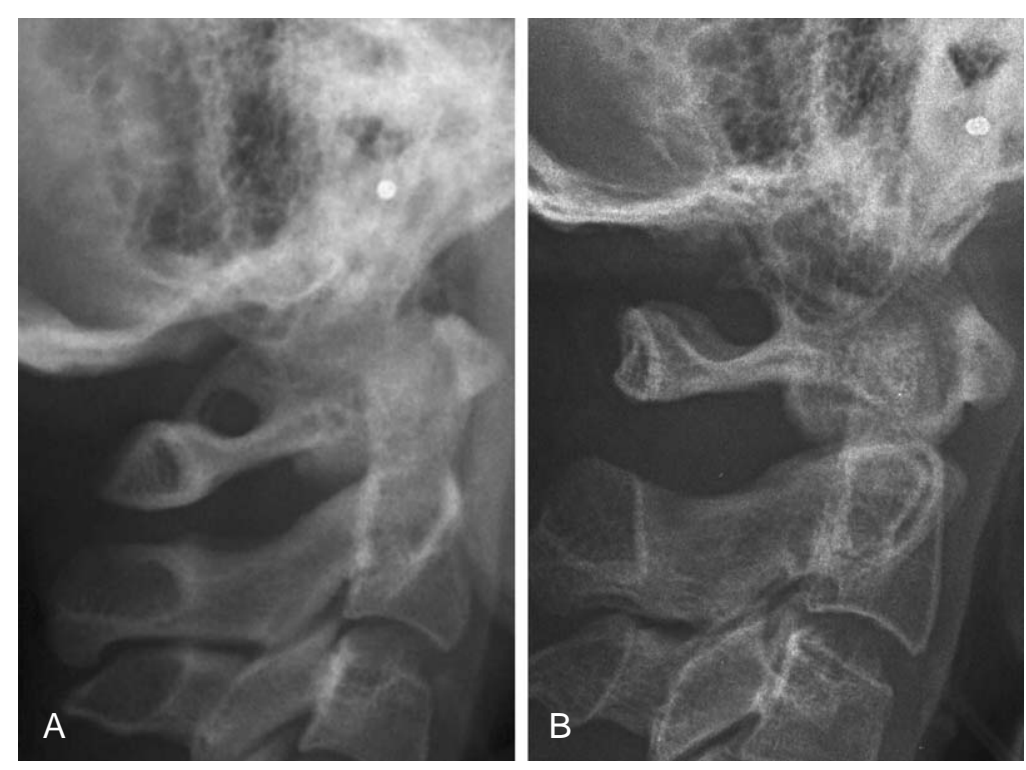

Fig. 3. The complete (A) and partial (B) ponticuli posticus seen on lateral cephalometric head radiographs. Mistaking this anomaly as a broad posterior arch of the atlas and placing a screw in the posterior arch could lead to injury to the vertebral artery. 
in the classical entry point at the junction of the posterior arch and the lateral mass ${ }^{6.7}$ causes significant bleeding from the epidural plexus and can possibly cause irritation to the C2 nerve root resulting in occipital neuralgia, some surgeons recommend placing the screw higher, starting in the posterior aspect of the posterior $\operatorname{arch}^{8}$. A broad posterior arch of the atlas is the best indication for this modified screw trajectory. However, in patients having a ponticulus posticus, it can be mistaken for a broad posterior arch, and the surgeon may put the screw into the ponticulus posticus. This could result in an injury to the vertebral artery which is trapped in the arcuate foramen and can scarcely escape injury by the probe, drill bit, tap, and/or screw. Vertebral artery injury may not cause any symptoms if the patient and the surgeon are lucky, but otherwise, it can lead to stroke or even death by thrombosis, embolism, or arterial dissection. Considering the significance of this grave complication, we need to investigate the morphological characteristics and prevalence of the ponticulus posticus.

In the western population, the prevalence of ponticulus posticus has been reported to be between $5.1 \%$ and $37.8 \%^{3-5}$. However, as far as we know, the only study on its prevalence in an Asian population is from India'. This study analyzed north Indians, many of whom are presumed to be Aryan. Therefore, we examined the three-dimensional CT scan images of Korean people. We were astonished that as much as $26 \%$ of the patient population had ponticulus posticus, because we had not noticed through our daily practice that its prevalence was so high. Most of these patients took a CT scan because of cervical spine problems, and patients who had upper cervical problems including congenital anomalies were not uncommon among them. Therefore, we presumed that these patients did not represent the whole population. So we then examined lateral cephalometric head radiographs of dental patients which were taken regardless of presence or absence of cervical symptoms. Surprisingly, this examination revealed $14 \%$ prevalence of ponticulus posticus. We think that the statistically significant difference $(\mathrm{p}=0.0007)$ in prevalence between the two groups was not only due to different patient populations but also influenced by the different diagnostic values of CT scans and radiographs. In any case, we found that ponticulus posticus is not a rare anomaly in Koreans, just as it is not in the Western population. Therefore, lateral radiographs should be carefully examined to check for the presence of this anomaly before screw placement in the lateral mass of the atlas in order to avoid vertebral artery injury.
In addition, we found that 20 patients (7\%) had small spicules resembling mild partial ponticuli on radiographs (Fig. 4). We did not classify them as partial ponticuli because the spicules were not large, but they might have been a mild form of partial ponticulus posticus. Importantly, in these patients, the lateral portion of the posterior arch tended to be thin and low while the thickness of the posterior portion tended to look normal (Fig. 4). If a surgeon did not take a careful look at this morphological characteristic seen on the radiograph and put a screw in the posterior arch, it could result in a vertebral artery injury or fracture or weakness of this portion.

Examination of the three-dimensional CT images revealed a various spectra of shapes and sizes of the ponticulus posticus. We also found that even the ponticulus lateralis was not uncommon. This wide variation of shapes, sizes and location of the ponticuli seems to be natural, considering they are normal occurrence in the quadrupeds and act as an additional extension for the attachment of the posterior atlantooccipital membrane $e^{2}$. In any case, ponticulus posticus can have a wide variation in shapes and sizes and we cannot ascertain its three dimensional morphology on each side of an individual patient without three-dimensional CT images. Therefore, when the ponticulus posticus is

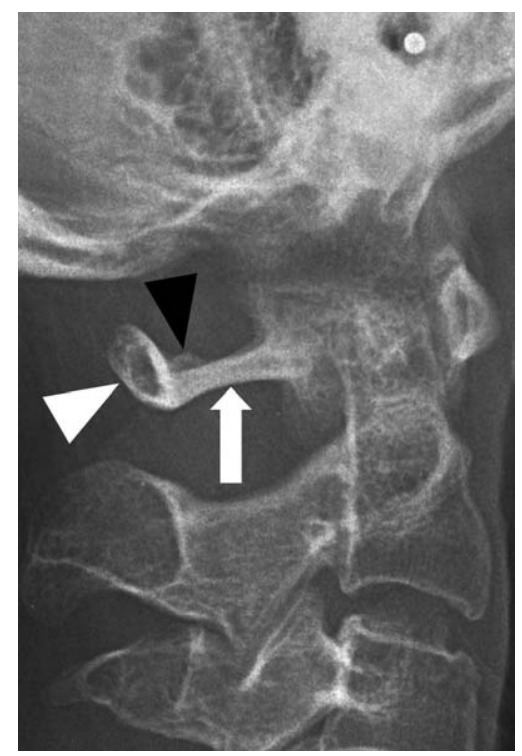

Fig. 4. A lateral radiograph showing a small spicule (black arrowhead) on the posterior arch which might be a mildest form of ponticulus posticus. Note that the lateral portion of the posterior arch (white arrow) is thin and low while the height of the posterior portion of the posterior arch (white arrowhead) looks normal. If a screw insertion is started at the posterior portion of the posterior arch (white arrowhead), it could injure the vertebral artery. 
observed or suspected on the lateral radiograph of a patient who requires lateral mass screw placement in the atlas, we may have two options. One is to put the screws under the posterior arch in the classic way ${ }^{6,7}$. If placing screws in the posterior $\operatorname{arch}^{8}$ is desired, we recommend taking a threedimensional CT scan and checking the size and shape of the ponticulus on each side in order to avoid vertebral artery injury. Since these patients will require screw fixation at other levels of the cervical spine or the occiput, CT scans will be helpful planning for placement of these screws as well.

\section{Conclusions}

The ponticulus posticus is not an uncommon anomaly in Korean people, though its prevalence in other Asian races remains unknown. Therefore, the presence of this anomaly should be carefully ruled out on lateral radiographs before screw placement in the lateral mass of the atlas in order to avoid vertebral artery injury. Because ponticulus posticus has a wide spectra of shapes and sizes which cannot be exactly determined using other studies, we recommend taking a three-dimensional CT scan when a ponticulus posticus is suspected or observed on the radiographs of a patient in whom lateral mass screw placement in the posterior arch of the atlas is planned.

\section{Acknowledgements}

We thank and acknowledge Ms. Yoon Ju Kwon and Ms. Seung Min You, who are spine research coordinators of our institution, for the contribution of their time and effort in retrieving and archiving the $\mathrm{CT}$ dataset and digital radiographic images.

\section{REFERENCES}

1. Hasan M, Shukla S, Siddiqui MS, Singh D: Posterolateral tunnels and ponticuli in human atlas vertebrae. J Anat 2001; 199: 339-343.

2. Cushing KE, Ramesh V, Gardner-Medwin D, et al: Tethering of the vertebral artery in the congenital arcuate foramen of the atlas vertebra: a possible cause of vertebral artery dissection in children. Dev Med Child Neurol 2001; 43: 491-496.

3. Wight S, Osborne N, Breen AC: Incidence of ponticulus posterior of the atlas in migraine and cervicogenic headache. J Manipulative Physiol Ther 1999; 22: 15-20.

4. Young JP, Young PH, Ackermann MJ, Anderson PA, Riew KD: The ponticulus posticus: implications for screw insertion into the first cervical lateral mass. J Bone Joint Surg Am 2005; 87: 2495-2498.

5. Stubbs DM: The arcuate foramen. Variability in distribution related to race and sex. Spine 1992; 17: 1502-1504.

6. Goel A, Desai KI, Muzumdar DP: Atlantoaxial fixation using plate and screw method: a report of 160 treated patients. Neurosurgery 2002; 51: 1351-1356.

7. Harms J, Melcher RP: Posterior C1-C2 fusion with polyaxial screw and rod fixation. Spine 2001; 26: $2467-$ 2471.

8. Ma XY, Yin QS, Wu ZH, Xia H, Liu JF, Zhong SZ: Anatomic considerations for the pedicle screw placement in the first cervical vertebra. Spine 2005; 30: 1519-1523. 